\title{
Correction to: Beiträge zur Algebra und Geometrie: half a century
}

\section{Horst Martini ${ }^{1}$}

Published online: 19 April 2021

(c) The Managing Editors 2021

\section{Correction to: Beitr Algebra Geom https://doi.org/10.1007/s13366-021-00569-0}

In the original article, the author affiliation is wrongly updated and the correct affiliation should be University of Technology Chemnitz, Chemnitz, Germany

Publisher's Note Springer Nature remains neutral with regard to jurisdictional claims in published maps and institutional affiliations.

The original article can be found online at https://doi.org/10.1007/s13366-021-00569-0.

\section{Horst Martini}

horst.martini@mathematik.tu-chemnitz.de

1 University of Technology Chemnitz, Chemnitz, Germany 